\title{
Commentary
}

\section{Seven facts and five initiatives for gut microbiome research}

\author{
Danyi $\mathrm{Li}^{1}$, Chunhui Gao ${ }^{1}$, Faming Zhang ${ }^{2,3,4}$, Ruifu Yang ${ }^{5}$, Canhui Lan ${ }^{1}$, Yonghui Ma ${ }^{6 \bowtie}$, Jun Wang ${ }^{7 凶}$ \\ ${ }^{1}$ Beijing Rexinchang Biotechnology Research Institute Co. Ltd, Beijing 100011, China \\ ${ }^{2}$ Medical Center for Digestive Diseases, The Second Affiliated Hospital of Nanjing Medical University, Nanjing 210011, China \\ ${ }^{3}$ Key Lab of Holistic Integrative Enterology, Nanjing Medical University, Nanjing 210011, China \\ ${ }^{4}$ Division of Microbiotherapy, Sir Run Run Shaw Hospital, Nanjing Medical University, Nanjing 211166, China \\ ${ }^{5}$ State Key Laboratory of Pathogen and Biosecurity, Beijing Institute of Microbiology and Epidemiology, Beijing 100071, China \\ ${ }^{6}$ Centre for Bioethics, Medical College, Xiamen University, Xiamen 361102, China \\ ${ }^{7}$ CAS Key Laboratory of Pathogenic Microbiology and Immunology, Institute of Microbiology, Chinese Academy of Science, \\ Beijing 100101, China \\ \ Correspondence: yhma@xmu.edu.cn (Y. Ma), junwang@im.ac.cn (J. Wang)
}

The gut microbiome has attracted increasing attention over the past 15 years. Along with the fast-growing body of research literature and media reports, the public's opinions on the gut microbiome have begun to appear polarized.

Some believe that the gut microbiome is at the core of human health and is related to every single disease. To the opposite, some people question the scientific basis of gut microbiome studies and criticize that many of them are farfetched; there is even a joke spreading in the biomedical research field-"keeping gut microbiome in mind, no mechanism is hard to find".

However, neither view is impartial. Here, we present seven facts about the gut microbiome research, and provide five initiatives to promote the healthy development of this field.

\section{FACT 1. THE GUT MICROBIOME IS THE LEADING EDGE OF SCIENTIFIC RESEARCH}

There are more than 50,000 gut microbiome research articles in the database of Web of Science since 2000. Prior to 2005, the relevant publications averaged no more than 500 per year. However, as of December 18, 2019, there are already more than 9,500 publications year-to-date, which has grown about 30 times since 2000, 6 times since 2010, and doubled since 2015 (Fig. 1).

Among these publications, more than 2,000 are highly cited (the top one percent in each of the $22 \mathrm{ESI}$ subject areas per year), published in 449 journals. The top 15 journals with the most highly cited articles are Nature, Gut, Science, PNAS, Cell Host \& Microbe, Gastroenterology, Cell, PloS One, ISME Journal, Nature Communications, Nature
Reviews Microbiology, Nature Reviews Gastroenterology \& Hepatology, Nutrients, Immunity, and Nature Medicine.

More than 170 countries and regions around the world contributed to these highly cited studies, with universal participation by major countries including the USA, China, United Kingdom, Germany, France, Canada, Italy, Japan, Spain, Netherlands, Australia, etc. Among them, China's contribution (including Hong Kong, Macao and Taiwan) has made considerable progress in the past decade (Fig. 2).

Behind the rise of gut microbiome research is the rapid development of cutting-edge biological research technologies (Gilbert et al., 2016; Gilbert et al., 2018), including germfree animal models (Uzbay, 2019), next-generation sequencing technologies (Shendure et al., 2017), and multiomics approaches (Quince et al., 2017; Lagier et al., 2018; Zhang et al., 2019) such as metagenomics, metatranscriptomics, metabolomics, and culturomics. The development and application of these technologies not only enable researchers to analyze composition and structure of gut microbiome, but also make it possible to study and verify the function of the microbiome and its association with health and disease from different interdisciplinary perspectives.

\section{FACT 2. BASIC AND TRANSLATIONAL RESEARCH OF THE GUT MICROBIOME IS EXPANDING GLOBALLY}

The rapid development of the gut microbiome research in recent years is not only related to the scientific community's 


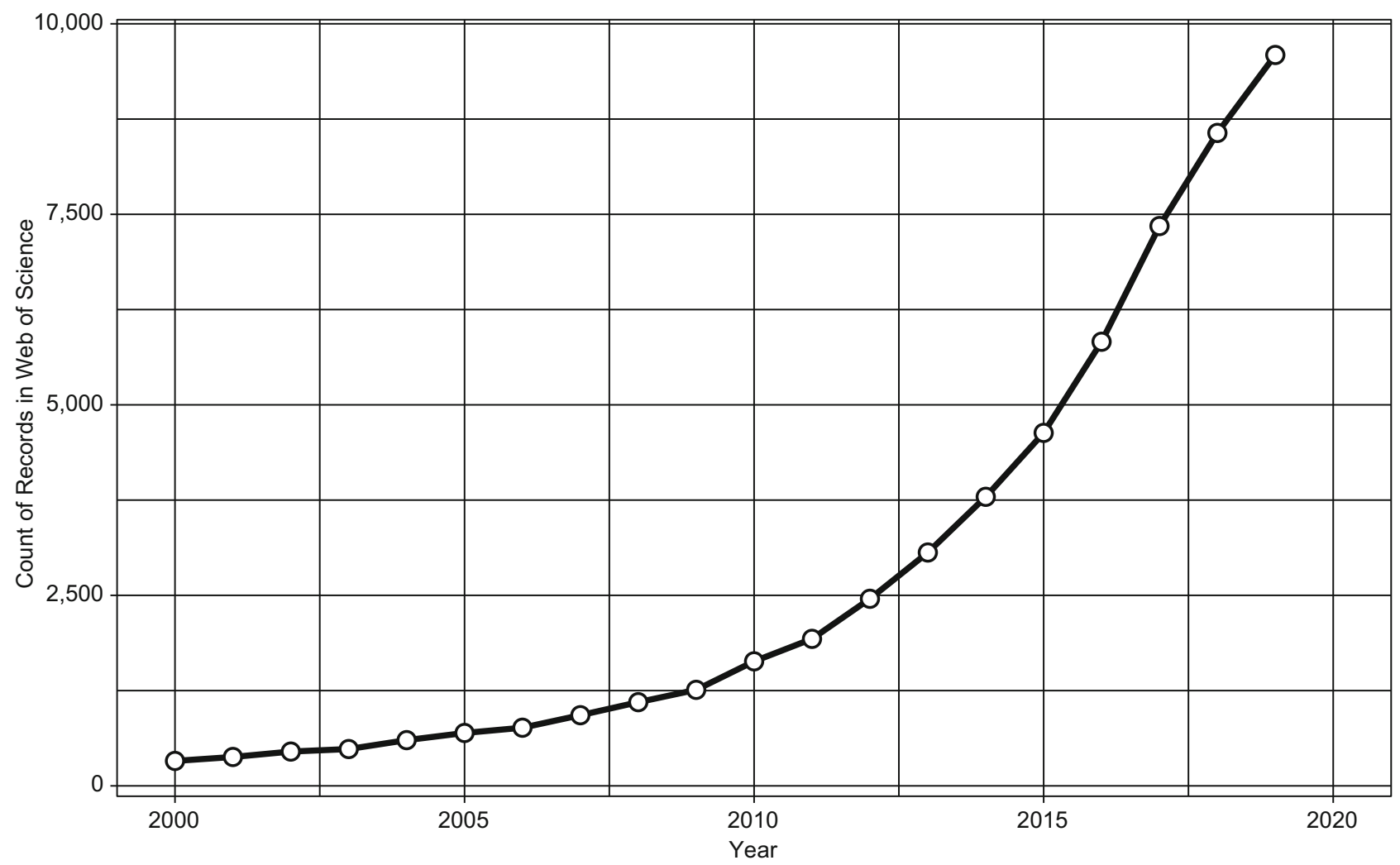

Figure 1. Growth of gut microbiome studies in Web of Science database. Query "TS = (gut OR intestine OR bowel OR intestinal OR colon OR colorectal OR gastrointestine OR gastrointestinal) AND TS = (microbiome OR microbiota OR flora OR microbe OR microbes OR commensal OR symbiont OR pathobiont OR mycobiome OR virome OR metagenome OR meta-genome)" and then retrieve those published from 2000-2019. Database accessed on Dec. 18, 2019.

deepening understanding of the function of the microbiome, but also inseparable from each nation's strategic support.

Of these, the Human Microbiome Project (HMP) supported by the United States' National Institutes of Health (NIH) is best known. Between 2007 and 2016, NIH invested a total of $\$ 215$ million in HMP (Proctor, 2019), with an additional $\$ 728$ million for other human microbiome studies from 2012 to 2016 (NIH Human Microbiome Portfolio Analysis Team, 2019). China, the United Kingdom, Germany, Canada, France, and other countries and regions also continue to increase investment. It is estimated that the global investment in microbiome-related research over the past decade has exceeded \$ 1.7 billion (Proctor, 2019).

At the same time, industrialization and commercialization of gut microbiome-related application is also progressing. The establishment of related biotechnology companies has sprung up, with considerable global investment. As of 2019, more than $\$ 3$ billion has been invested in gut microbiomerelated innovation companies. Similar to basic research, the United States took the lead with more than $\$ 2.4$ billion in investment, and other countries are catching up (Fig. 3).

\section{FACT 3. THE GUT MICROBIOME CONTRIBUTES TO HEALTH AND DISEASES}

The pivotal role of the gastrointestinal (GI) tract in health forms the basis for the gut microbiome to participate in host physiological processes and even affect human health and disease (Goldszmid and Trinchieri, 2012). Besides its role in the digestion, absorption, and metabolism of food and nutrients, the gut is an important immune and endocrine organ (Rehfeld, 1998; Weiner et al., 2011; Gribble and Reimann, 2019). In addition, it is also known as "the second brain" with a complex enteric nervous system which communicates with the brain via the vagus nerve (Mayer, 2011; Avetisyan et al., 2015; Yoo and Mazmanian, 2017).

Gut microbiome studies are now transforming from correlation to causation, with the efforts to address the mechanisms by which the microbiome influences host health (Gilbert et al., 2018; Schmidt et al., 2018). In their Nature paper published in 2006 , by using fecal microbiota transplantation in mice, the Gordon lab demonstrated for the first time that host obesity phenotype can be affected and transmitted by the gut microbiome (Turnbaugh et al., 2006). 


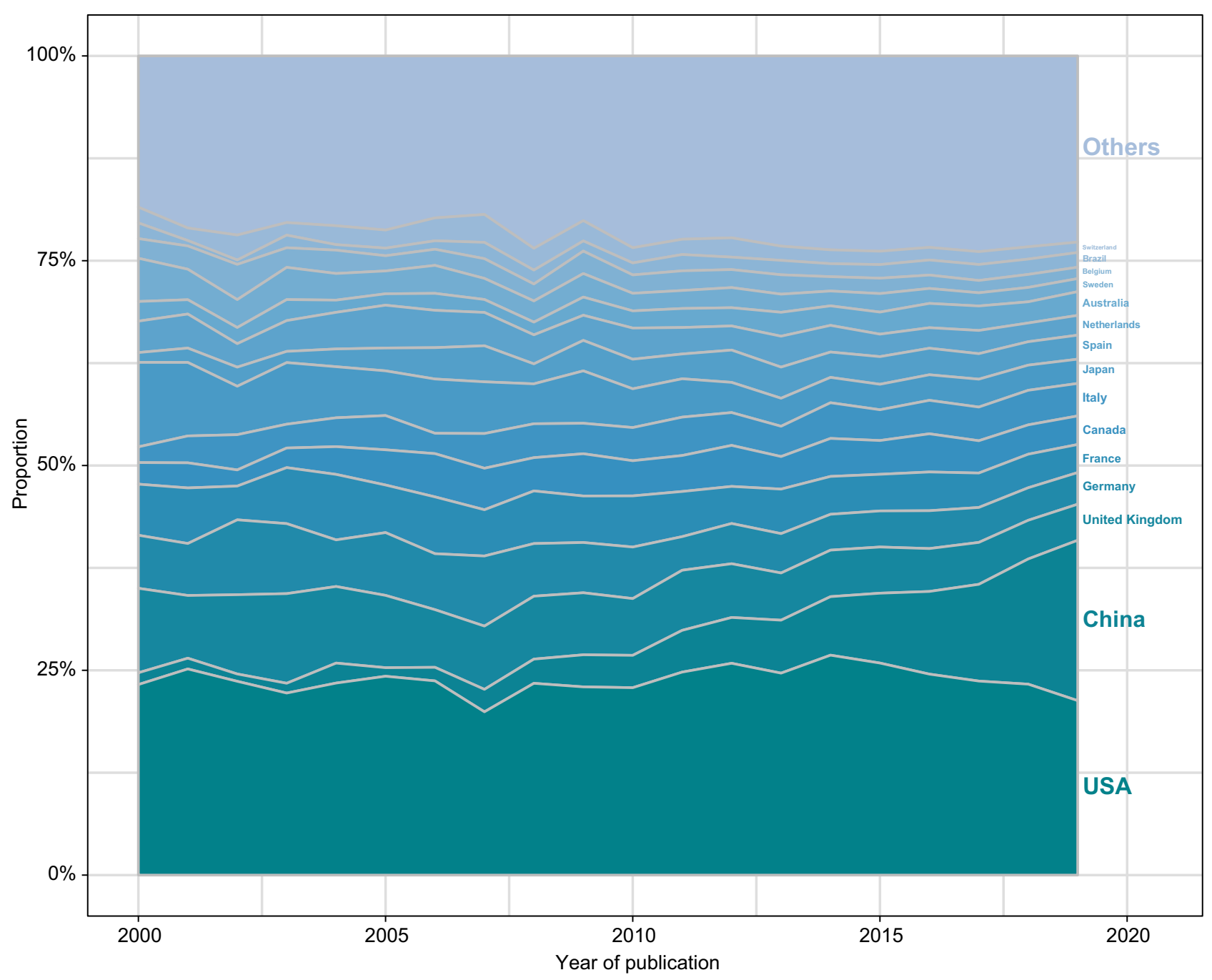

Figure 2. Proportion of country contributions.

Since then, growing evidence confirms that the gut microbiome can be considered the "microbial organ" of the body (O'Hara and Shanahan, 2006; Byndloss and Bäumler, 2018), acting through multiple mechanisms (e.g., microbiotaderived metabolites (Schroeder and Bäckhed, 2016; Dalile et al., 2019) and microbial translocation (Manfredo Vieira et al., 2018; Meisel et al., 2018)) to communicate with the host and regulate host physiology at both local and systemic levels. It is believed that the gut microbiome can affect host metabolism (Tilg et al., 2020), immunity (Belkaid and Harrison, 2017), endocrine (Rooks and Garrett, 2016; Rastelli et al., 2019), and neural function (Sharon et al., 2016) and thus contribute to host susceptibility to a series of diseases (Sekirov et al., 2010; Clemente et al., 2012; Nicholson et al., 2012; Lynch and Pedersen 2016), such as obesity (Le Chatelier et al., 2013; Ridaura et al., 2013), diabetes (Qin et al., 2012), fatty liver diseases (Canfora et al., 2019), cardiovascular diseases (Schiattarella et al., 2017), autoimmune and inflammatory diseases (Clemente et al., 2018),

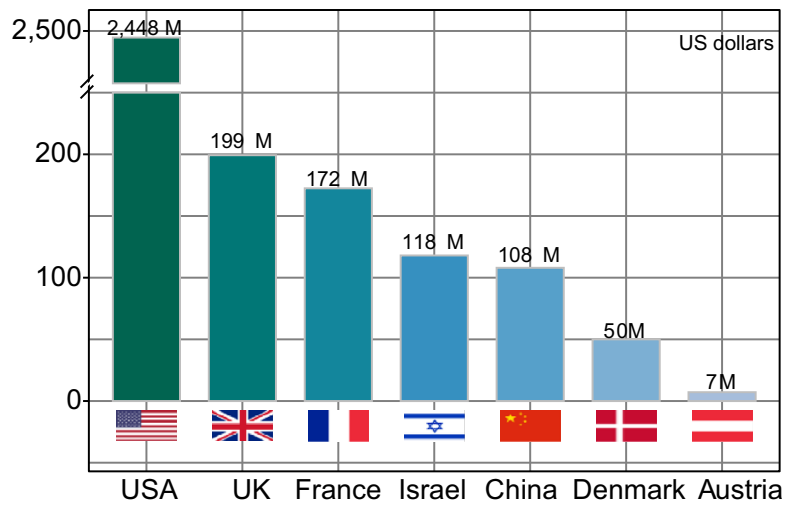

Figure 3. Financing of gut microbiota-related companies in different countries (from public data).

psychological and neurological disorders (Cryan et al., 2020), and cancer (Garrett, 2015; Yu and Schwabe, 2017; Vitiello et al., 2019). 
In addition to the discovery of pathology and disease mechanisms, gut microbiome research also promotes the development of novel diagnosis and therapeutic interventions (Gilbert et al., 2018).

Gut microbiota-related biomarkers can potentially be used for colorectal cancer and adenoma screening, and can increase the accuracy of current non-invasive screening methods when used combinedly (Wong and Yu, 2019). Restoration of the gut microbiome by fecal microbiota transplantation (FMT) has proven effective in treating recurrent $C$. difficile infection and is also a potential treatment for inflammatory bowel disease and other diseases (Vaughn et al., 2019). Dietary fiber intervention can improve type 2 diabetes through selectively promoting short-chain fatty acid-producing bacteria (Zhao et al., 2018); and microbiota-directed complementary food seems a promising approach for treating childhood undernutrition (Gehrig et al., 2019).

The gut microbiome is also a key factor in personalized medicine. For example, a machine-learning algorithm that integrates gut microbiota and other anthropometric parameters can predict personalized postprandial glycemic response (Zeevi et al., 2015). In addition, targeting specific overgrowing pathobiont is a promising strategy to treat the corresponding disease (Duan et al., 2019; Yuan et al., 2019).

Furthermore, gut microbiome can also influence the effect of drugs and therapies by participating in drug metabolism and affecting host immune response (Skelly et al., 2019; Zimmermann et al., 2019a, b); and it has been shown that lab animals that are too "clean" are not optimal models for drug development (Rosshart et al., 2019).

\section{FACT 4. GUT DYSBIOSIS IS ONLY ONE FACTOR IN DISEASE}

Although plenty of work has shown that the gut microbiome plays a crucial role in human health, other factors, such as genetics, environmental exposure, and lifestyle, can also influence disease risk (Franks and McCarthy, 2016; Hall et al., 2017; Gentile and Weir, 2018; Scott et al., 2019). It has been speculated that, in some cases, gut microbiome abnormality may be not the root cause of disease but rather a mediating factor or a bystander (Hanage, 2014; Franks and McCarthy, 2016; Crow, 2018; Inamo, 2019; Jia et al., 2019).

For diabetes, obesity, and other metabolic diseases that are closely related to the gut microbiome (Qin et al., 2012; Le Chatelier et al., 2013; Ridaura et al., 2013; Komaroff, 2017; Schiattarella et al., 2017), it is still unclear how much the microbiome contributes to disease initiation and progression. The development of these diseases is more likely a combined result of different driving factors (Keith et al., 2006; Franks and McCarthy, 2016; Chatterjee et al., 2017), including genetic susceptibility, dietary habits, physical activity, early life influences, sleep, and medication.
Food allergy is another condition that correlates with changes in the gut microbiome (Iweala and Nagler, 2019). There are reports that microbiome-based interventions, such as probiotics, prebiotics, and fecal microbiota transplantation, may help reduce symptoms (Bunyavanich, 2019). However, the risk of allergic disease is also influenced by a series of factors (Iweala and Nagler, 2019). In addition to genetic predisposition, other early life factors including caesarean section, preterm birth, antibiotic usage, environmental pollution, infections, and maternal smoking and excessive drinking can all contribute to the development of food allergy (Reynolds and Finlay, 2017; Mitselou et al., 2018; Levin et al., 2019) and need to be considered for disease prevention and treatment (Tordesillas et al., 2017).

When talking about gut microbiome-associated diseases, such as diarrhea (Singh et al., 2018), inflammatory bowel disease (Piovani et al., 2019), irritable bowel syndrome (Ford et al., 2017), cardiovascular disease (Miller et al., 2017), autism (Bai et al., 2019), Alzheimer's disease (Kivipelto et al., 2018), Parkinson's disease (Ascherio and Schwarzschild, 2016), it is important to keep in mind that the gut microbiome is only one aspect of the disease, and we should avoid overemphasizing its importance.

\section{FACT 5: GUT MICROBIOME RESEARCH IS STILL AT ITS INFANCY}

What we know so far about gut microbiome might still just be the tip of the iceberg, and many limitations, inconclusive findings and controversies still exist within this field.

Inter-personal gut microbiome is highly individualized, and even within the same individual, gut microbiome is highly dynamic within short term, thus we still lack a good definition of "healthy microbiome". This missing baseline data or definition also hinders many of the translational and interventional research (Lloyd-Price et al., 2016).

Besides bacteria, we also need to consider the impact of phages (Shkoporov and Hill, 2019), archaea (Pennisi 2017) and fungi (Richard and Sokol, 2019) in the Gl tract on host health and diseases. Researches into those topics are still at a relative early stage. How do we study their function and potential roles of vast unknown and/or uncultured microbes? Metagenomics and culturomics are improving constantly and facilitate such analyses, yet many remain to be done (Nayfach et al., 2019).

Also, can animal studies be translated directly to humans? Probably not, as recently the US firm Synlogic has created an engineered bacteria strain and treated phenylketonuria in mouse models (Isabella et al., 2018), yet it failed in the human clinical trial, suggesting a direct and simple translation is not feasible.

How to resolve the standardization and repeatability issues in microbiome research? Such essential issues call for even more scientists to work at a global scale for standardization in methodology and more open databases to be 
shared among researchers (Servick, 2016; Costea et al., 2017; Poussin et al., 2018; Schloss, 2018).

How about long-term safety in microbiome intervention approaches such as prebiotics, probiotics and fecal-material transplantation? Recent researches have indicated that many of the interventions carry potential risks (Singh et al., 2018; Suez et al., 2018; DeFilipp et al., 2019; Yelin et al., 2019). And how do we manipulate microbiome with precision? One example might be personalized nutrition research and translation (Zmora et al., 2016; Johnson et al., 2019) and it has gained attention, yet this has to be done on large number of individuals and to be tracked over a longer time.

Thus, it is fair to conclude that microbiome research is still in its infancy, more thorough research with better methods has to be carried out to determine the role as well as mechanisms of gut microbiome in human health and diseases, plus the efficacy and safety of interventional approaches.

\section{FACT 6: CHAOS AND CONFLICT OF INTEREST EXIST IN GUT MICROBIOME RESEARCH}

Due to inappropriate self-publicity and interpretation of certain researchers, combined with the further exaggeration of many media and commercial partners, many of the gut microbiome research results and microbiome-based research products have been labeled erroneously to be the new panacea, capable of treating all kinds of illness. This idea was even adopted by many of the radical researchers. Such extreme kind of concept is for sure detrimental for the gut microbiome research and industry.

Currently, the golden standard for evaluating drug safety and efficacy is randomized, controlled clinical trials (Bothwell and Podolsky, 2016; Djulbegovic and Guyatt, 2017), which has also been used to evaluate gut microbiome related interventions. Yet in reality, randomized controlled trials (RCTs) are limited by individual differences, short term of intervention etc when it comes to evaluating prebiotics and probiotics (Zeilstra et al., 2018), and functional evidence is also limited to deepen the insights into mechanisms (Guarino and Canani, 2016).

In such context, exaggeration of the probiotics' efficacy, misplacing the function of whole gut microbiome by just a few products, and abuse of research products, as well as ignoring the complexity of gut microbiome by over-simplifying study design and interventional approaches are among the common phenomena in this field (Crow, 2018).

In addition, in commercial activities there are cases of promoting probiotics towards immune-deficient populations, which is potentially risky (Cohen, 2018). In fact, special population including ICU patients (Yelin et al., 2019) and hospitalized elderly (Dauby, 2017) are at risk of bacteraemia when intake probiotics, and in extreme cases, immune-deficient elderly could develop hepatapostema and bacteraemia after long-term ingestion of yogurts (Pararajasingam and Uwagwu, 2017).

Also, when the essential question remains unanswered regarding the baseline healthy microbiome's characteristics, the concept of gut microbiome dysregulation or dysbiosis has been abused, to lure the consumers and patients to purchase microbiome-related products (Shanahan and Hill, 2019).

Besides, we need to be alerted by the conflict of commercial interests within research. For instance, food industry sponsored nutritional research (Mozaffarian, 2017), or even those by public health research organization (Galea and Saitz, 2017), professional associations or societies (Nissen, 2017), those who set the standards (Sox, 2017) all could be affected by different interests (Greenhalgh, 2019). Nutritional analyses and meta-analyses might also be manipulated to cover the negative effects of certain products (Barnard et al., 2017).

Under such circumstances, many of the claims by infant dairy products including promoting cognitive capacity and safeguarding intestinal health lack sufficient scientific evidence (Hughes et al., 2017). Yet how to regulate such issues remains a difficult task for regulatory bodies including the US FDA (The Lancet null, 2019).

\section{FACT 7: SELF-PURIFICATION AND DISCIPLINE MECHANISMS EXIST IN GUT MICROBIOME RESEARCH}

Many of experts in this field have realized that the recent zealousness might lead to a topic bubble, and the call for strengthening self-purification and discipline also gained support, with a few such recommendations being issued via scientific journals.

First of all, experts call for the principle of caution and critics regarding microbiome research (Hanage, 2014; Crow, 2018). For instance, the description of research results has to be accurate and faithful, and avoid over-interpretation regarding non-causal studies as well as animal studies. While accumulating evidence over causality, we also need to deepen the microbiome research into the level of bacterial strains and bacterial genes, to gain insights onto the exact mechanisms (Fischbach, 2018). This is particularly important for the field of probiotics (Kleerebezem et al., 2019). Plus, researchers are also working on the standardization of procedure and methodology in microbiome research (Knight et al., 2018).

Another new task is to regulate effectively all the diverse upcoming approaches in microbiome intervention (Aagaard and Hohmann, 2019). Many recommendations were issued regarding interventional approaches including probiotics with potential risks (Cohen, 2018) and FMT (Hoffmann et al., 2017; Verbeke et al., 2017), as well as novel food products targeting microbiome and aiming at microbiome health (Green et al., 2017). 
The public are expected to understand, appreciate and eventually participate into the microbiome research and translation, while the research and translation themselves have to effectively avoid risk and safety issues (DominguezBello et al., 2016; Shamarina et al., 2017). It is widely accepted that ethics has to be obeyed during the process of research and translation (O'Doherty et al., 2016; Rhodes 2016).

It is not without solution when it comes to the complex, multi-faceted conflict of interests issues, as pointed out by scholars (Stead, 2017). For instance, many of the recommendations have been made that the health policy making process should not be influenced by food industries' interests (Untangle food industry influences on health 2019), scientific researchers should disclose actively and fully their own potential conflict of interest (Thornton, 2017), and medical professionals should disclose such conflicts to patients as well (Zuger, 2017).

Thus, it is obvious that a fully functioning self-purification and discipline mechanism has been established among the scientific bodies of microbiome researchers, covering the design and execution of research, means of regulation and biological ethics.

\section{FIVE INITIATIVES}

Based on the above 7 facts about gut microbiome, in particular, we propose below five initiatives for basic researchers, clinicians, and industrial professionals in relevant fields:

\section{Follow the normative ethical principles to carry out research}

We propose that research activities related to gut microbiome should be subject to necessary ethical review and peer review.

Researchers should learn, practice and respect bioethical principles, adhere to scientific spirit, scientific culture and research ethics; on the basis of truth-seeking and rational criticism, researchers should strive to be innovative and responsible; researchers should adjust the relationship between themselves and collaborators (including other researchers, funders, research subjects, general public/consumers) and objects (including experimental animals, ecological environment, etc.) in a timely manner, and also take social responsibility.

\section{Avoid hype and packaging}

We propose that basic researchers, clinicians, industry and media professionals should avoid hype and over-promoting/packaging of gut microbiome and themselves, and actively participate in self-discipline and self-purifying in the whole field.

Researchers should avoid using their affiliated insititutions, and their position endorsement to create personal influence, refrain from self-marketing, and also avoid exaggerating or over-promoting individual or team's research results. In the publicity work of scientific research, industry, and social media, we should avoid the labeling gut microbiome as "panacea" or "useless"; we oppose opportunism, clickbait, and sensationalising the hot topic; we oppose the "vulgarization" and "pseudoscientization" of gut microbiome research, including the abuse of the concept of "gut microbiome" to irrelevant fields, or promise unrealistic effects, etc.

\section{Disclose conflict of interest and reveal safety and risk issues actively}

We propose that researchers actively disclose the conflict of interest in various occasions, such as publishing papers, academic speeches, media publicity, etc., and at the same time, if there are potential safety risks in related products and services, they should proactively inform consumers or patients.

In both research and translational application, it is important to maintain openness and transparency during risk recognition, assessment, risk management and damage control. Researchers actively disclose conflict of interest would not only be beneficial for individuals, but also for the brand accumulated value and dissemination of products and/or services. Meanwhile, if researchers can actively inform patients/ consumers about the safety risks, this will also increase brand trusts and credibility of individuals, products or services, and effectively avoid bringing risks to consumers/patients, thus reducing the systematic risks of whole industry.

Abide by laws and disciplines and adhere to evidencebased scientific rules

We propose to strictly abide by national laws and regulations and adhere to evidence-based scientific rules in the process of industrialization. The function, efficacy, and health benefit claims of a specific product or service must comply with the relevant national laws and regulations, and must never break the legal and ethical bottom line. The promotion of function and efficacy of a particular products or services should be based on high-quality evidence, and the evidence of RCT should be developed and accumulated. We should not overinterpret the results generated from cell and animal experiments, whereas also pay special attention to the risks of side effects and unintended consequences.

Actively participate in science popularization and education and promote public participation

We call on professionals to actively participate in science popularization, dissemination and education activities for the public, meanwhile also consciously absorb public opinions 
and encourage the public to participate in and contribute to scientific research equally.

In the face of the rapid development of gut microbiome research and fast growing of knowledge update and accumulation, there are a mix of hope, help, and hype, which sometimes make people confused. Furthermore, the area of gut microbiome is increasingly influenced and even dominated by commercial market and capitals, which may put public interest at stake. Therefore, established and mainstream front-line experts are urgently needed to participate in popular science activities. In the daily science communication work, professionals can systematically popularize the relevant knowledge of gut microbiota, whereas in case of big events, they should respond to the public's concerns in a timely and transparent manner and ultimately to achieve a responsible and sustainable supportive environment for research.

\section{ACKNOWLEDGEMENTS}

This work was supported by National Key Research and Development Program of China (2018YFC2000500), the Strategic Priority Research Program of the Chinese Academy of Sciences (XDB29020000), the National Natural Science Foundation of China (31771481, 91857101), and the National Social Science Foundation of China (16CZX064). We thank Prof. Liping Zhao from Shanghai Jiao Tong University for insightful advice and the many researchers, clinicians and industry specialists who participated in the discussion and provided valuable suggestions.

\section{ABBREVIATIONS}

FDA, Food and Drug Administration; FMT, fecal microbiota transplantation; HMP, Human Microbiome Project; ICU, intensive care unit; NIH, National Institutes of Health; RCT, randomized controlled trial.

\section{COMPLIANCE WITH ETHICS GUIDELINES}

Danyi Li, Chunhui Gao, Faming Zhang, Ruifu Yang, Canhui Lan, Yonghui Ma, and Jun Wang declare that they have no conflict of interest. This article does not contain any studies with human or animal subjects performed by any of the authors.

\section{OPEN ACCESS}

This article is licensed under a Creative Commons Attribution 4.0 International License, which permits use, sharing, adaptation, distribution and reproduction in any medium or format, as long as you give appropriate credit to the original author(s) and the source, provide a link to the Creative Commons licence, and indicate if changes were made. The images or other third party material in this article are included in the article's Creative Commons licence, unless indicated otherwise in a credit line to the material. If material is not included in the article's Creative Commons licence and your intended use is not permitted by statutory regulation or exceeds the permitted use, you will need to obtain permission directly from the copyright holder. To view a copy of this licence, visit http:// creativecommons.org/licenses/by/4.0/.

\section{REFERENCES}

Aagaard K, Hohmann E (2019) Regulating microbiome manipulation. Nat Med 25(6):874-876

Ascherio A, Schwarzschild MA (2016) The epidemiology of Parkinson's disease: risk factors and prevention. Lancet Neurol 15 (12):1257-1272

Avetisyan M, Schill EM, Heuckeroth RO (2015) Building a second brain in the bowel. J Clin Invest 125(3):899-907

Bai D, Yip BHK, Windham GC, Sourander A, Francis R, Yoffe R, Glasson E, Mahjani B, Suominen A, Leonard H et al (2019) Association of genetic and environmental factors with autism in a 5-country cohort. JAMA Psychiatry. https://doi.org/10.1001/ jamapsychiatry.2019.1411

Barnard ND, Willett WC, Ding EL (2017) The misuse of metaanalysis in nutrition research. JAMA 318(15):1435-1436

Belkaid Y, Harrison OJ (2017) Homeostatic immunity and the microbiota. Immunity 46(4):562-576

Bothwell LE, Podolsky SH (2016) The emergence of the randomized, controlled trial. N Engl J Med 375(6):501-504

Bunyavanich S (2019) Food allergy: could the gut microbiota hold the key? Nat Rev Gastroenterol Hepatol 16(4):201-202

Byndloss MX, Bäumler AJ (2018) The germ-organ theory of noncommunicable diseases. Nat Rev Microbiol 16(2):103-110

Canfora EE, Meex RCR, Venema K, Blaak EE (2019) Gut microbial metabolites in obesity, NAFLD and T2DM. Nat Rev Endocrinol 15 (5):261-273

Chatterjee S, Khunti K, Davies MJ (2017) Type 2 diabetes. Lancet Lond Engl 389(10085):2239-2251

Clemente JC, Ursell LK, Parfrey LW, Knight R (2012) The impact of the gut microbiota on human health: an integrative view. Cell 148 (6):1258-1270

Clemente JC, Manasson J, Scher JU (2018) The role of the gut microbiome in systemic inflammatory disease. BMJ 360:j5145

Cohen PA (2018) Probiotic safety-no guarantees. JAMA Intern Med 178(12):1577-1578

Costea PI, Zeller G, Sunagawa S, Pelletier E, Alberti A, Levenez F, Tramontano M, Driessen M, Hercog R, Jung F-E et al (2017) Towards standards for human fecal sample processing in metagenomic studies. Nat Biotechnol 35(11):1069-1076

Crow D (2018) Microbiome research in a social world. Cell 172 (6):1143-1145

Cryan JF, O'Riordan KJ, Sandhu K, Peterson V, Dinan TG (2020) The gut microbiome in neurological disorders. Lancet Neurol 19 (2):179-194

Dalile B, Van Oudenhove L, Vervliet B, Verbeke K (2019) The role of short-chain fatty acids in microbiota-gut-brain communication. Nat Rev Gastroenterol Hepatol 16(8):461-478

Dauby N (2017) Risks of Saccharomyces boulardii-containing probiotics for the prevention of clostridium difficile infection in the elderly. Gastroenterology 153(5):1450-1451 
DeFilipp Z, Bloom PP, Torres Soto M, Mansour MK, Sater MRA, Huntley MH, Turbett S, Chung RT, Chen Y-B, Hohmann EL (2019) Drug-resistant E. coli bacteremia transmitted by fecal microbiota transplant. N Engl J Med 381(21):2043-2050

Djulbegovic B, Guyatt GH (2017) Progress in evidence-based medicine: a quarter century on. Lancet Lond Engl 390 (10092):415-423

Dominguez-Bello MG, Peterson D, Noya-Alarcon O, Bevilacqua M, Rojas N, Rodríguez R, Pinto SA, Baallow R, Caballero-Arias $\mathrm{H}$ (2016) Ethics of exploring the microbiome of native peoples. Nat Microbiol 1(7):16097

Duan Y, Llorente C, Lang S, Brandl K, Chu H, Jiang L, White RC, Clarke TH, Nguyen K, Torralba M et al (2019) Bacteriophage targeting of gut bacterium attenuates alcoholic liver disease. Nature 575(7783):505-511

Fischbach MA (2018) Microbiome: focus on causation and mechanism. Cell 174(4):785-790

Ford AC, Lacy BE, Talley NJ (2017) Irritable bowel syndrome. N Engl J Med 376(26):2566-2578

Franks PW, McCarthy MI (2016) Exposing the exposures responsible for type 2 diabetes and obesity. Science 354(6308):69-73

Galea S, Saitz R (2017) Funding, institutional conflicts of interest, and schools of public health: realities and solutions. JAMA 317 (17):1735-1736

Garrett WS (2015) Cancer and the microbiota. Science 348 (6230):80-86

Gehrig JL, Venkatesh S, Chang H-W, Hibberd MC, Kung VL, Cheng J, Chen RY, Subramanian S, Cowardin CA, Meier MF et al (2019) Effects of microbiota-directed foods in gnotobiotic animals and undernourished children. Science 365(6449):eaau4732

Gentile CL, Weir TL (2018) The gut microbiota at the intersection of diet and human health. Science 362(6416):776-780

Gilbert JA, Quinn RA, Debelius J, Xu ZZ, Morton J, Garg N, Jansson JK, Dorrestein PC, Knight R (2016) Microbiome-wide association studies link dynamic microbial consortia to disease. Nature 535 (7610):94-103

Gilbert JA, Blaser MJ, Caporaso JG, Jansson JK, Lynch SV, Knight $\mathrm{R}$ (2018) Current understanding of the human microbiome. Nat Med 24(4):392-400

Goldszmid RS, Trinchieri G (2012) The price of immunity. Nat Immunol 13(10):932-938

Green JM, Barratt MJ, Kinch M, Gordon JI (2017) Food and microbiota in the FDA regulatory framework. Science 357 (6346):39-40

Greenhalgh S (2019) Making China safe for coke: how Coca-Cola shaped obesity science and policy in China. BMJ 364:k5050

Gribble FM, Reimann F (2019) Function and mechanisms of enteroendocrine cells and gut hormones in metabolism. Nat Rev Endocrinol 15(4):226-237

Guarino A, Canani RB (2016) Probiotics in childhood diseases: from basic science to guidelines in 20 years of research and development. J Pediatr Gastroenterol Nutr 63(Suppl 1):S1-S2

Hall AB, Tolonen AC, Xavier RJ (2017) Human genetic variation and the gut microbiome in disease. Nat Rev Genet 18(11):690-699

Hanage WP (2014) Microbiology: microbiome science needs a healthy dose of scepticism. Nature 512(7514):247-248
Hoffmann D, Palumbo F, Ravel J, Roghmann M-C, Rowthorn V, von Rosenvinge E (2017) Improving regulation of microbiota transplants. Science 358(6369):1390-1391

Hughes HK, Landa MM, Sharfstein JM (2017) Marketing claims for infant formula: the need for evidence. JAMA Pediatr 171(2):105106

Inamo J (2019) Non-causal association of gut microbiome on the risk of rheumatoid arthritis: a Mendelian randomisation study. Ann Rheum Dis. https://doi.org/10.1136/annrheumdis-2019-216565

Isabella VM, Ha BN, Castillo MJ, Lubkowicz DJ, Rowe SE, Millet YA, Anderson CL, Li N, Fisher AB, West KA et al (2018) Development of a synthetic live bacterial therapeutic for the human metabolic disease phenylketonuria. Nat Biotechnol 36(9):857-864

Iweala OI, Nagler CR (2019) The microbiome and food allergy. Annu Rev Immunol 37:377-403

Jia J, Dou P, Gao M, Kong X, Li C, Liu Z, Huang T (2019) Assessment of causal direction between gut microbiota-dependent metabolites and cardiometabolic health: a bidirectional mendelian randomization analysis. Diabetes 68(9):1747-1755

Johnson AJ, Vangay P, Al-Ghalith GA, Hillmann BM, Ward TL, Shields-Cutler RR, Kim AD, Shmagel AK, Syed AN, Personalized Microbiome Class Students et al (2019) Daily sampling reveals personalized diet-microbiome associations in humans. Cell Host Microbe 25(6):789-802.e5

Keith SW, Redden DT, Katzmarzyk PT, Boggiano MM, Hanlon EC, Benca RM, Ruden D, Pietrobelli A, Barger JL, Fontaine KR et al (2006) Putative contributors to the secular increase in obesity: exploring the roads less traveled. Int J Obes 2005 30(11):15851594

Kivipelto M, Mangialasche F, Ngandu T (2018) Lifestyle interventions to prevent cognitive impairment, dementia and Alzheimer disease. Nat Rev Neurol 14(11):653-666

Kleerebezem M, Binda S, Bron PA, Gross G, Hill C, van Hylckama Vlieg JE, Lebeer S, Satokari R, Ouwehand AC (2019) Understanding mode of action can drive the translational pipeline towards more reliable health benefits for probiotics. Curr Opin Biotechnol 56:55-60

Knight R, Vrbanac A, Taylor BC, Aksenov A, Callewaert C, Debelius J, Gonzalez A, Kosciolek T, McCall L-I, McDonald D et al (2018) Best practices for analysing microbiomes. Nat Rev Microbiol 16 (7):410-422

Komaroff AL (2017) The microbiome and risk for obesity and diabetes. JAMA 317(4):355-356

Lagier J-C, Dubourg G, Million M, Cadoret F, Bilen M, Fenollar F, Levasseur A, Rolain J-M, Fournier P-E, Raoult D (2018) Culturing the human microbiota and culturomics. Nat Rev Microbiol 16 (9):540-550

Le Chatelier E, Nielsen T, Qin J, Prifti E, Hildebrand F, Falony G, Almeida M, Arumugam M, Batto J-M, Kennedy $S$ et al (2013) Richness of human gut microbiome correlates with metabolic markers. Nature 500(7464):541-546

Levin ME, Botha M, Basera W, Facey-Thomas HE, Gaunt B, Gray CL, Kiragu W, Ramjith J, Watkins A, Genuneit J (2020) Environmental factors associated with allergy in urban and rural children from the South AFrican Food Allergy (SAFFA) cohort. J Allergy Clin Immunol 145(1):415-426 
Lloyd-Price J, Abu-Ali G, Huttenhower C (2016) The healthy human microbiome. Genome Med 8(1):51

Lynch SV, Pedersen O (2016) The human intestinal microbiome in health and disease. N Engl J Med 375(24):2369-2379

Manfredo Vieira S, Hiltensperger M, Kumar V, Zegarra-Ruiz D, Dehner C, Khan N, Costa FRC, Tiniakou E, Greiling T, Ruff W et al (2018) Translocation of a gut pathobiont drives autoimmunity in mice and humans. Science 359(6380):1156-1161

Mayer EA (2011) Gut feelings: the emerging biology of gut-brain communication. Nat Rev Neurosci 12(8):453-466

Meisel M, Hinterleitner R, Pacis A, Chen L, Earley ZM, Mayassi T, Pierre JF, Ernest JD, Galipeau HJ, Thuille N et al (2018) Microbial signals drive pre-leukaemic myeloproliferation in a Tet2-deficient host. Nature 557(7706):580-584

Miller V, Mente A, Dehghan M, Rangarajan S, Zhang X, Swaminathan S, Dagenais G, Gupta R, Mohan V, Lear S et al (2017) Fruit, vegetable, and legume intake, and cardiovascular disease and deaths in 18 countries (PURE): a prospective cohort study. Lancet Lond Engl 390(10107):2037-2049

Mitselou N, Hallberg J, Stephansson O, Almqvist C, Melén E, Ludvigsson JF (2018) Cesarean delivery, preterm birth, and risk of food allergy: nationwide Swedish cohort study of more than 1 million children. J Allergy Clin Immunol 142(5):1510-1514.e2

Mozaffarian D (2017) Conflict of interest and the role of the food industry in nutrition research. JAMA 317(17):1755-1756

Nayfach S, Shi ZJ, Seshadri R, Pollard KS, Kyrpides NC (2019) New insights from uncultivated genomes of the global human gut microbiome. Nature 568(7753):505-510

Nicholson JK, Holmes E, Kinross J, Burcelin R, Gibson G, Jia W, Pettersson S (2012) Host-gut microbiota metabolic interactions. Science 336(6086):1262-1267

NIH Human Microbiome Portfolio Analysis Team (2019) A review of 10 years of human microbiome research activities at the US National Institutes of Health, Fiscal Years 2007-2016. Microbiome 7(1):31

Nissen SE (2017) Conflicts of interest and professional medical associations: progress and remaining challenges. JAMA 317 (17):1737-1738

O'Doherty KC, Virani A, Wilcox ES (2016) The human microbiome and public health: social and ethical considerations. Am J Public Health 106(3):414-420

O'Hara AM, Shanahan F (2006) The gut flora as a forgotten organ. EMBO Rep 7(7):688-693

Pararajasingam A, Uwagwu J (2017) Lactobacillus: the not so friendly bacteria. BMJ Case Rep 2017:bcr-2016-218423

Pennisi E (2017) Survey of archaea in the body reveals other microbial guests. Science 358(6366):983

Piovani D, Danese S, Peyrin-Biroulet L, Nikolopoulos GK, Lytras T, Bonovas S (2019) Environmental risk factors for inflammatory bowel diseases: an umbrella review of meta-analyses. Gastroenterology 157(3):647-659.e4

Poussin C, Sierro N, Boué S, Battey J, Scotti E, Belcastro V, Peitsch MC, Ivanov NV, Hoeng J (2018) Interrogating the microbiome: experimental and computational considerations in support of study reproducibility. Drug Discov Today 23(9):1644-1657

Proctor L (2019) Priorities for the next 10 years of human microbiome research. Nature 569(7758):623-625
Qin J, Li Y, Cai Z, Li S, Zhu J, Zhang F, Liang S, Zhang W, Guan Y, Shen $D$ et al (2012) A metagenome-wide association study of gut microbiota in type 2 diabetes. Nature 490(7418):55-60

Quince C, Walker AW, Simpson JT, Loman NJ, Segata N (2017) Shotgun metagenomics, from sampling to analysis. Nat Biotechnol 35(9):833-844

Rastelli M, Cani PD, Knauf C (2019) The gut microbiome influences host endocrine functions. Endocr Rev 40(5):1271-1284

Rehfeld JF (1998) The new biology of gastrointestinal hormones. Physiol Rev 78(4):1087-1108

Reynolds LA, Finlay BB (2017) Early life factors that affect allergy development. Nat Rev Immunol 17(8):518-528

Rhodes R (2016) Ethical issues in microbiome research and medicine. BMC Med 14(1):156

Richard ML, Sokol H (2019) The gut mycobiota: insights into analysis, environmental interactions and role in gastrointestinal diseases. Nat Rev Gastroenterol Hepatol 16(6):331-345

Ridaura VK, Faith JJ, Rey FE, Cheng J, Duncan AE, Kau AL, Griffin NW, Lombard V, Henrissat B, Bain JR et al (2013) Gut microbiota from twins discordant for obesity modulate metabolism in mice. Science. 341(6150):1241214

Rooks MG, Garrett WS (2016) Gut microbiota, metabolites and host immunity. Nat Rev Immunol 16(6):341-352

Rosshart SP, Herz J, Vassallo BG, Hunter A, Wall MK, Badger JH, McCulloch JA, Anastasakis DG, Sarshad AA, Leonardi I et al (2019) Laboratory mice born to wild mice have natural microbiota and model human immune responses. Science 365(6452): eaaw4361

Schiattarella GG, Sannino A, Toscano E, Giugliano G, Gargiulo G, Franzone A, Trimarco B, Esposito G, Perrino C (2017) Gut microbe-generated metabolite trimethylamine- $\mathrm{N}$-oxide as cardiovascular risk biomarker: a systematic review and dose-response meta-analysis. Eur Heart J 38(39):2948-2956

Schloss PD (2018) Identifying and overcoming threats to reproducibility, replicability, robustness, and generalizability in microbiome research. mBio 9(3):e00525-18

Schmidt TSB, Raes J, Bork P (2018) The human gut microbiome: from association to modulation. Cell 172(6):1198-1215

Schroeder BO, Bäckhed F (2016) Signals from the gut microbiota to distant organs in physiology and disease. Nat Med 22(10):10791089

Scott AJ, Alexander JL, Merrifield CA, Cunningham D, Jobin C, Brown R, Alverdy J, O'Keefe SJ, Gaskins HR, Teare J et al (2019) International Cancer Microbiome Consortium consensus statement on the role of the human microbiome in carcinogenesis. Gut 68(9):1624-1632

Sekirov I, Russell SL, Antunes LCM, Finlay BB (2010) Gut microbiota in health and disease. Physiol Rev 90(3):859-904

Servick K (2016) Of mice and microbes. Science 353(6301):741743

Shamarina D, Stoyantcheva I, Mason CE, Bibby K, Elhaik E (2017) Communicating the promise, risks, and ethics of large-scale, open space microbiome and metagenome research. Microbiome 5(1):132

Shanahan F, Hill C (2019) Language, numeracy and logic in microbiome science. Nat Rev Gastroenterol Hepatol 16(7):387388 
Sharon G, Sampson TR, Geschwind DH, Mazmanian SK (2016) The central nervous system and the gut microbiome. Cell 167(4):915932

Shendure J, Balasubramanian S, Church GM, Gilbert W, Rogers J, Schloss JA, Waterston RH (2017) DNA sequencing at 40: past, present and future. Nature 550(7676):345-353

Shkoporov AN, Hill C (2019) Bacteriophages of the human gut: the "known unknown" of the microbiome. Cell Host Microbe 25 (2):195-209

Singh P, Mitsuhashi S, Ballou S, Rangan V, Sommers T, Cheng V, Iturrino-Moreda J, Friedlander D, Nee J, Lembo A (2018a) Demographic and dietary associations of chronic diarrhea in a representative sample of adults in the United States. Am J Gastroenterol 113(4):593-600

Singh V, Yeoh BS, Chassaing B, Xiao X, Saha P, Aguilera Olvera R, Lapek JD, Zhang L, Wang W-B, Hao S et al (2018b) Dysregulated microbial fermentation of soluble fiber induces cholestatic liver cancer. Cell 175(3):679-694.e22

Skelly AN, Sato Y, Kearney S, Honda K (2019) Mining the microbiota for microbial and metabolite-based immunotherapies. Nat Rev Immunol 19(5):305-323

Sox HC (2017) Conflict of interest in practice guidelines panels. JAMA 317(17):1739-1740

Stead WW (2017) The complex and multifaceted aspects of conflicts of interest. JAMA 317(17):1765-1767

Suez J, Zmora N, Zilberman-Schapira G, Mor U, Dori-Bachash M, Bashiardes S, Zur M, Regev-Lehavi D, Ben-Zeev Brik R, Federici $S$ et al (2018) Post-antibiotic gut mucosal microbiome reconstitution is impaired by probiotics and improved by autologous FMT. Cell 174(6):1406-1423.e16

The Lancet null (2019) Dietary supplement regulation: FDA's bitter pill. Lancet Lond Engl 393(10173):718

Thornton JP (2017) Conflict of interest and legal issues for investigators and authors. JAMA 317(17):1761-1762

Tilg H, Zmora N, Adolph TE, Elinav E (2020) The intestinal microbiota fuelling metabolic inflammation. Nat Rev Immunol 20 (1):40-54

Tordesillas L, Berin MC, Sampson HA (2017) Immunology of food allergy. Immunity 47(1):32-50

Turnbaugh PJ, Ley RE, Mahowald MA, Magrini V, Mardis ER, Gordon Jl (2006) An obesity-associated gut microbiome with increased capacity for energy harvest. Nature 444(7122):10271031

Untangle food industry influences on health (2019) Nat Med 25 (11): 1629

Uzbay T (2019) Germ-free animal experiments in the gut microbiota studies. Curr Opin Pharmacol 49:6-10

Vaughn BP, Rank KM, Khoruts A (2019) Fecal microbiota transplantation: current status in treatment of gi and liver disease. Clin Gastroenterol Hepatol Off Clin Pract J Am Gastroenterol Assoc 17(2):353-361
Verbeke F, Janssens Y, Wynendaele E, De Spiegeleer B (2017) Faecal microbiota transplantation: a regulatory hurdle? BMC Gastroenterol 17(1):128

Vitiello GA, Cohen DJ, Miller G (2019) Harnessing the microbiome for pancreatic cancer immunotherapy. Trends Cancer 5(11):670-676

Weiner HL, da Cunha AP, Quintana F, Wu H (2011) Oral tolerance. Immunol Rev 241(1):241-259

Wong SH, Yu J (2019) Gut microbiota in colorectal cancer: mechanisms of action and clinical applications. Nat Rev Gastroenterol Hepatol 16(11):690-704

Yelin I, Flett KB, Merakou C, Mehrotra P, Stam J, Snesrud E, Hinkle M, Lesho E, McGann P, McAdam AJ et al (2019) Genomic and epidemiological evidence of bacterial transmission from probiotic capsule to blood in ICU patients. Nat Med 25(11):1728-1732

Yoo BB, Mazmanian SK (2017) The enteric network: interactions between the immune and nervous systems of the gut. Immunity 46(6):910-926

Yu L-X, Schwabe RF (2017) The gut microbiome and liver cancer: mechanisms and clinical translation. Nat Rev Gastroenterol Hepatol 14(9):527-539

Yuan J, Chen C, Cui J, Lu J, Yan C, Wei X, Zhao X, Li N, Li S, Xue G et al (2019) Fatty liver disease caused by high-alcohol-producing Klebsiella pneumoniae. Cell Metab 30(6):1172

Zeevi D, Korem T, Zmora N, Israeli D, Rothschild D, Weinberger A, Ben-Yacov O, Lador D, Avnit-Sagi T, Lotan-Pompan $M$ et al (2015) Personalized nutrition by prediction of glycemic responses. Cell 163(5):1079-1094

Zeilstra D, Younes JA, Brummer RJ, Kleerebezem M (2018) Perspective: fundamental limitations of the randomized controlled trial method in nutritional research: the example of probiotics. Adv Nutr Bethesda Md 9(5):561-571

Zhang X, Li L, Butcher J, Stintzi A, Figeys D (2019) Advancing functional and translational microbiome research using metaomics approaches. Microbiome 7(1):154

Zhao L, Zhang F, Ding X, Wu G, Lam YY, Wang X, Fu H, Xue X, Lu $\mathrm{C}$, Ma J et al (2018) Gut bacteria selectively promoted by dietary fibers alleviate type 2 diabetes. Science 359(6380):1151-1156

Zimmermann M, Zimmermann-Kogadeeva M, Wegmann R, Goodman AL (2019a) Separating host and microbiome contributions to drug pharmacokinetics and toxicity. Science 363(6427):eaat9931

Zimmermann M, Zimmermann-Kogadeeva M, Wegmann R, Goodman AL (2019b) Mapping human microbiome drug metabolism by gut bacteria and their genes. Nature 570(7762):462-467

Zmora N, Zeevi D, Korem T, Segal E, Elinav E (2016) Taking it personally: personalized utilization of the human microbiome in health and disease. Cell Host Microbe 19(1):12-20

Zuger A (2017) What do patients think about physicians' conflicts of interest?: watching transparency evolve. JAMA 317(17):17471748 